\title{
Informatização na cadeia produtiva da piscicultura brasileira: inovações tecnológicas em softwares, aplicativos, programas de monitoramento e rastreabilidade
}

\author{
Computerization in the Brazilian fish farming production chain: technological innovations in
}

software, applications, monitoring and traceability programs

Informatización en la cadena productiva piscícola brasileña: innovaciones tecnológicas en software, aplicaciones, programas de seguimiento y trazabilidad

\section{Resumo}

O pescado produzido na aquicultura tem sido fundamental para o abastecimento global de proteína animal na alimentação humana. No Brasil a aquicultura vem crescendo e para que se consolide se faz necessária a informatização no processo de produção do pescado no campo, no processamento que ocorre na indústria desde o recebimento da matéria prima até a expedição do produto acabado e no setor de distribuição desses produtos, com destaque para a rastreabilidade. Diante disso, o objetivo do estudo foi realizar levantamento de dados sobre a disponibilidade de sistemas informatizados na cadeia produtiva do pescado brasileiro, buscando por inovações tecnológicas, softwares, aplicativos, programas de monitoramento e rastreabilidade. Existem tecnologias disponíveis para a aquicultura como é o caso da identificação eletrônica dos peixes, dos aplicativos para o processo de produção, dos softwares como AgroPesca na indústria e Alumi Pescados no setor de distribuição do pescado e dos códigos bidimensionais (QR Code) que tem sido utilizados para fornecer aos consumidores informação rápida sobre os produtos adquiridos. Com a aplicação de novas tecnologias no setor, os mercados consumidores tendem a ter maior confiança em adquirir o pescado brasileiro.

Palavras-chave: Aquicultura; Aplicativo; Indústria do pescado; Piscicultura; Software.

\begin{abstract}
Fish produced in Aquaculture has been critical to the global supply of animal protein in human food. In Brazil, Aquaculture has been growing and in order for it to be consolidated it is necessary to computerize the fish production process in the field, in the processing that takes place in the industry, from the receipt of raw material to the shipment of the finished product and in the distribution sector of these products, with emphasis on traceability. Therefore, the objective of the study was to carry out data collection on the availability of computerized systems in the Brazilian fish production chain, looking for technological innovations, software, applications, monitoring and traceability programs. There are technologies available for aquaculture, such as electronic fish identification, applications for the production process, software such as AgroPesca in the industry and Alumi Pescados in the fish distribution sector and the twodimensional codes (QR Code) that have been used to provide consumers with quick information about purchased products. With the application of new technologies in the sector, consumer markets tend to have greater confidence in purchasing Brazilian fish.
\end{abstract}

Keywords: Application; Aquaculture; Fish farming; Fish industry; Software. 


\begin{abstract}
Resumen
El pescado producido en la Acuicultura ha sido fundamental para el suministro mundial de proteína animal en la alimentación humana. En Brasil, la Acuicultura ha ido creciendo y para que se consolide es necesario informatizar el proceso de producción de pescado en el campo, en el procesamiento que se lleva a cabo en la industria, desde la recepción de la materia prima hasta el envío del producto terminado. producto y en el sector de distribución de estos productos, con énfasis en la trazabilidad. Por lo tanto, el objetivo del estudio fue realizar la recolección de datos sobre la disponibilidad de sistemas computarizados en la cadena de producción pesquera brasileña, buscando innovaciones tecnológicas, software, aplicaciones, programas de seguimiento y trazabilidad. Existen tecnologías disponibles para la acuicultura, como la identificación electrónica de peces, aplicaciones para el proceso de producción, software como AgroPesca en la industria y Alumi Pescados en el sector de distribución de pescado y los códigos bidimensionales (QR Code) que se han utilizado para brindar consumidores con información rápida sobre los productos comprados. Con la aplicación de nuevas tecnologías en el sector, los mercados consumidores tienden a tener mayor confianza en la compra de pescado brasileño.
\end{abstract}

Palabras clave: Acuicultura; Aplicación; Industria pesquera; Piscicultura; Software.

\title{
1. Introdução
}

O Brasil tem se destacado como produtor de alimentos e atualmente é o quarto maior exportador mundial de produtos agropecuários, atrás apenas da União Europeia, EUA e China. O país desponta ainda na produção de produtos de origem vegetal como soja, milho, cana-de-açúcar, café, algodão, suco de laranja e também na produção de produtos de origem animal como a carne bovina, carne de frango, carne suína e também o leite (CNA, 2020). Outro produto de origem animal que vem ganhando força no país é o pescado. Hoje o Brasil ocupa o $13^{\circ}$ lugar na produção de peixes em cativeiro (EMBRAPA, 2020).

Entende-se por pescado os peixes, os crustáceos, os moluscos, os anfíbios, os répteis, os equinodermos e outros animais aquáticos usados na alimentação humana (Brasil, 2017). A aquicultura tem a produção de mais rápido crescimento globalmente, e a carne de pescado é a mais consumida no mundo quando se soma pescado de captura e pescado de aquicultura (OECD/FAO, 2016). Em 2018 a produção global de pescado atingiu cerca de 179 milhões de toneladas dos quais 82 milhões de toneladas veio da produção da aquicultura, 156 milhões de toneladas foram usadas para consumo humano, registrando um abastecimento anual de 20,5kg per capta. Além disso, 22 milhões de toneladas foram destinadas para usos não alimentares como produção de farinha de peixe e óleo de peixe. A aquicultura foi responsável por $46 \%$ da produção total e $52 \%$ de pescado para consumo humano (FAO, 2020).

A produção de peixes de cultivo vem crescendo no Brasil com um salto de $31 \%$ de 2014 a 2019, atingindo 758.006 toneladas em 2019, sendo que os peixes nativos representam 38\% dessa produção. Juntamente com o crescimento na produção, a exportação de produtos da piscicultura no país também tem aumentado, e de 2015 a 2019 passou de 701 para 6.543 toneladas representando um crescimento de $833 \%$. Os peixes de cultivo e seus derivados são exportados principalmente para o Japão, China e Estados Unidos (Peixe BR, 2020).

Comparando-se a extensão territorial do Brasil com a dos países que atualmente se destacam como os maiores exportadores mundiais de produtos agropecuários como a União Europeia, EUA e China e observando também as condições de solo e clima e a disponibilidade de recursos hídricos, fica evidente que o Brasil tem muito a crescer na produção de alimentos (Cavali et al., 2021). Todo esse crescimento requer informatização e inovações tecnológicas, que quando existentes na cadeia produtiva do pescado podem alavancar o setor garantindo maior celeridade no processo de produção e qualidade do produto oferecido, gerando maior confiança tanto no mercado interno quanto externo.

Diante dos pressupostos, o objetivo do estudo foi realizar levantamento de dados sobre a disponibilidade de sistemas informatizados na cadeia produtiva do pescado brasileiro, buscando por inovações tecnológicas, softwares, aplicativos, programas de monitoramento e rastreabilidade. 


\section{Metodologia}

Esse estudo se trata de um estudo de levantamento de dados que se caracteriza como sendo do tipo descritivo exploratório, de caráter qualitativo, visando a análise, a comparação e o cruzamento de dados (Toledo \& Shiaishi, 2009), entre diversos artigos e literaturas relacionadas ao tema "a informatização da cadeia produtiva do pescado".

As buscas, armazenamento e análises de dados foram realizadas de agosto a outubro de 2021. As bases bibliográficas para realização das buscas foram Google Acadêmico <https://scholar.google.com.br/?hl=pt>, Scielo < https://www.scielo.br/>, periódicos da CAPES 〈https://www-periodicos-capes-gov-br.ezl.periodicos.capes.gov.br/index.php?> e repositórios institucionais. Os critérios adotados para as buscas foram periódicos/revistas científicos(as) com corpo técnico e editorial consolidado, e que apresentam foco e escopo relacionado ao tema. Além disso, possuindo vínculo com alguma instituição de ensino superior e conceito Qualis (2013- 2016) pelo menos B2, na área de avaliação Interdisciplinar < https://sucupira.capes.gov.br/sucupira/public/consultas/coleta/veiculoPublicacaoQualis/listaConsultaGeralPeriodicos.jsf $>$.

Os descritores utilizados foram Aquicultura, Pescado, Piscicultura, Tecnologias da informação; nos idiomas português e inglês, com palavras e termos separados pelos operadores booleanos 'AND' e 'OR' (Rocha et al., 2005; Pizzani et al., 2012), de acordo com os objetivos da busca em cada tópico deste artigo de revisão, i) Informatização no processo de produção do pescado, ii) Informatização no setor de processamento do pescado no Brasil, iii) Informatização no setor de distribuição do pescado e iv) Informatização no processo de rastreabilidade.

\section{Resultados e Discussão}

\subsection{Informatização no processo de produção do pescado}

Atualmente, planejar, manejar e controlar com eficiência qualquer empreendimento é essencial para alcançar bons resultados (Moreira \& Moreira, 2017) e por esse motivo o processo de produção do pescado no Brasil já conta com tecnologias avançadas que cada vez mais ganham espaço no setor. Todo o aporte de inovação tecnológica, principalmente do ano de 2010 até a atualidade, contribui de forma significativa para que a aquicultura se consolide, gerando enormes somas em receitas, distribuídas nas mais diversas atividades do ramo (Moreira \& Moreira, 2017). Um bom exemplo disso é a identificação eletrônica do peixe, que se trata de um dispositivo que é inserido na pele do espécime permitindo um registro eletrônico que é lido por um escâner, de modo a identificar o peixe no meio plantel. Depois de identificado é retirada uma amostra de tecido para análise do DNA, momento em que é realizado o levantamento de informações genéticas, que dão base para que o produtor evite cruzamentos consanguíneos, bem como possibilita selecionar os melhores perfis genéticos para matrizes (EMBRAPA, 2014).

Outro exemplo de inovação na produção de pescado é a ferramenta Aquisys v.1.3 que foi produzida pela EMBRAPA em parceria com outras instituições, e disponibilizada em plataforma online desde o seu lançamento em 2015 (Figura 1). Trata-se de um sistema informatizado que permite avaliar se o sistema de produção está de acordo com as boas práticas de manejo, além de oferecer orientações úteis ao sistema de produção e informações importantes de educação ambiental. $\mathrm{O}$ aplicativo possibilita ao produtor a aplicação correta de insumos, minimizando impactos negativos no ambiente e consequentemente no próprio sistema de produção (EMBRAPA, 2015). O sistema chegou a ser um dos três finalistas do Prêmio Inovação Aquícola 2019, na Categoria "Políticas Institucionais" (EMBRAPA, 2019). 
Figura 1 - nAquisys v.1.3 sistema informatizado que permite avaliar se o sistema de produção está de acordo com as boas práticas de manejo.

AQUISYS V.1.3 - SISTEMA INFORMATIZADO DE APOIO ÀS

BOAS PRÁTICAS DE MANEJO E GESTÃO AMBIENTAL DA AQUICULTURA

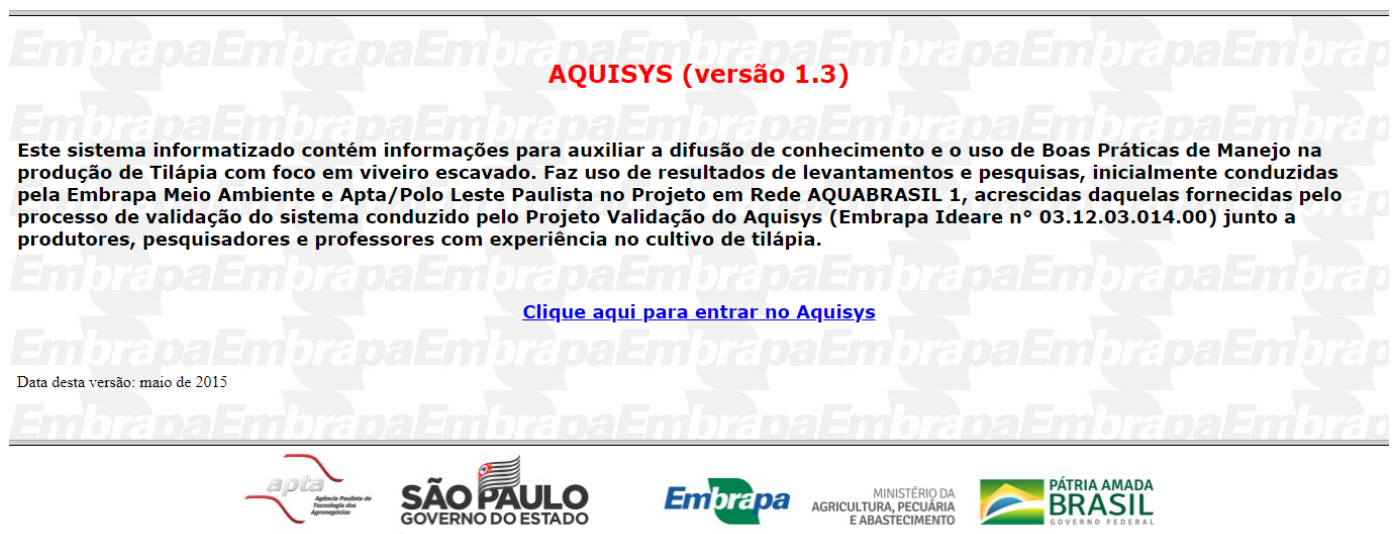

Fonte: EMBRAPA (2015).

No entanto, o aplicativo Aquímetro está disponível no Google Play e pode ser utilizado para a carcinicultura (Figura 2A). O aplicativo AquiNutri foi desenvolvido por professores e acadêmicos dos cursos de Engenharia de Aquicultura e Engenharia Agrícola da Universidade Federal da Grande Dourados (UFGD) e esse aplicativo pode ser utilizado para a realização de cálculos de fornecimento de ração de Tilápia, Pacu, Carpa e Tambaqui (Figura 2B).

Figura 2 - A) Aquímetro. B) AquiNuti.

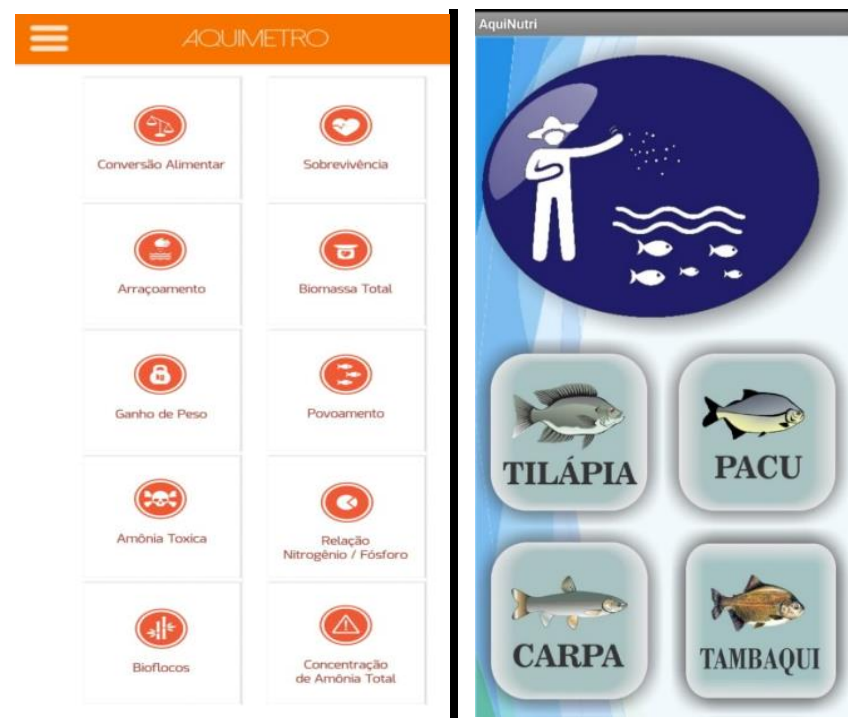

Fonte: Google Play.

Aquabit é um aplicativo pago e em português para camarões, peixes em cativeiro e ornamentais para a avaliação do sistema produtivo. É possível baixar uma versão para teste (Figura 3). 
Figura 3 - A) Aquabit.
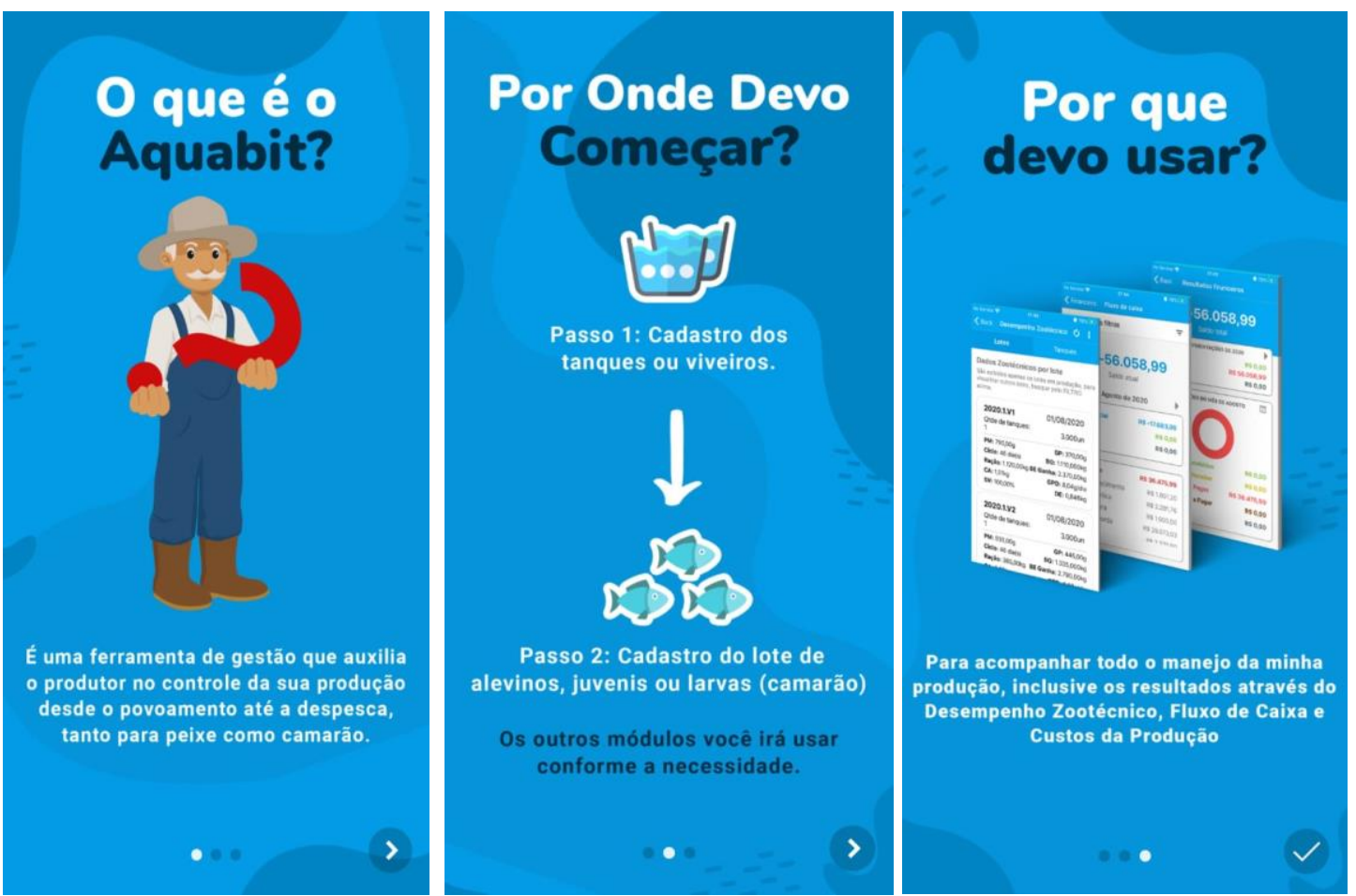

Fonte: Google Play.

Outros exemplos de aplicativos pagos e em português são o Aquaweb da FCA Tecnologia e o Inova Peixe. Este é um aplicativo para a avaliação do sistema produtivo de peixes enquanto aquele é um aplicativo que realiza o gerenciamento e armazenamento de dados da produção, com planilhas e gráficos prontos para camarões e peixes de cativeiro.

O BlueAqua é um aplicativo gratuito que está no idioma inglês e que pode ser utilizado para cálculos relacionados à produção de duas espécies de camarões: P. vannamei e P. monodon (Figura 4).

Figura 4 - BlueAqua.

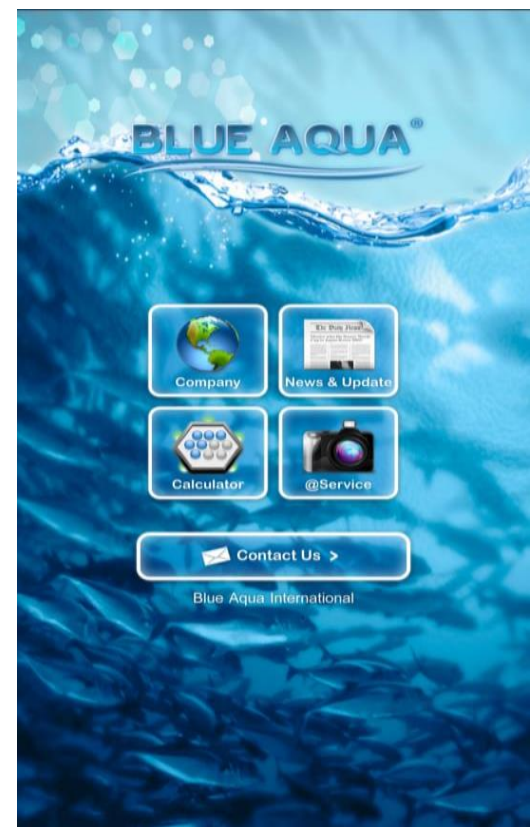

\begin{tabular}{l} 
Blue Aqua - Calculator - P vannamei \\
Please select calculator: \\
Total Biomass/ SR/ FCR \\
\hline SR (\%) \\
Daily Feed (kg) \\
ADG (g/day) \\
Free Ammonia (mg/l) \\
N:P Ratio \\
Aeration Performance \\
Aeration Costs (\$) \\
Water Pumping Costs (\$)
\end{tabular}

Fonte: Google Play. 
Growel Aqua 360 é um aplicativo gratuito e em inglês e que pode ser utilizado para o gerenciamento da aquicultura em sistemas de criação de camarões e peixes (Figura 5A). No etanto, o CIBA Shrimp Krishi é utilizado apenas para camarões (Figura $5 B)$.

Figura 5 - A) Growel Aqua 360. B) CIBA Shrimp Krishi.

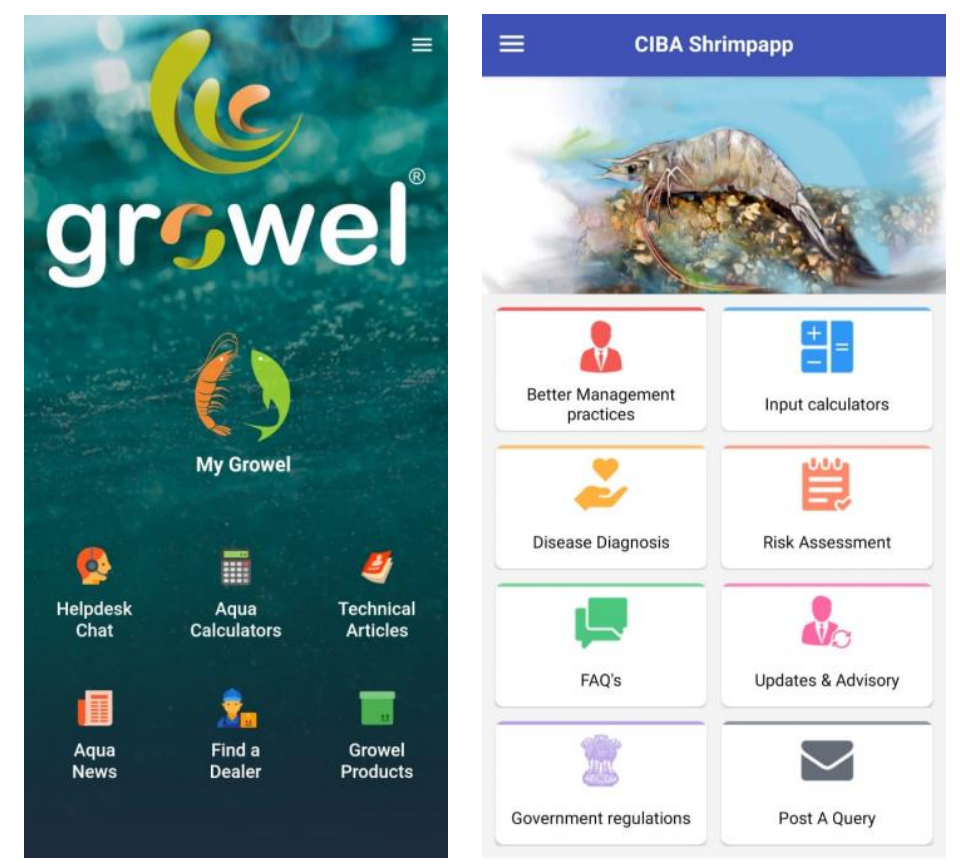

Fonte: Google Play.

Aquaconnect é um sistema utilizado por consultores em aquicultura para criadores de peixes e camarões e que utiliza inteligência artificial e tecnologias de sensoriamento remoto por satélite. $\mathrm{O}$ aplicativo é pago e em inglês e pode ser utilizado para inserir os dados que serão base para a avaliação do sistema de produção. Outro aplicativo pago e em inglês é o PondGuard que conecta um dispositivo aos tanques de aquicultura. Com ele é possível monitorar em tempo real dados de temperatura, oxigênio dissolvido e $\mathrm{pH}$ dos tanques de aquicultura.

Há também aplicativos educacionais gratuitos e em português como o AquaTilápia que é sobre as principais doenças bacterianas que acometem as Tilápias. São elas Columnariose por Flavobacterium columnare, Franciselose, Septicemia móvel, Septicemia por Edwardsiella sp., Septicemia por Streptococcus (Figura 6A) e o AquaSaúde que é sobre as principais doenças que acometem os camarões. São elas Síndrome da mancha branca, Mionecrose infecciosa, Necrose hipodermal e hematopoiética, Hepatopancreatite necrosante (Figura 6B). 
Research, Society and Development, v. 11, n. 2, e28911225543, 2022

(CC BY 4.0) | ISSN 2525-3409 | DOI: http://dx.doi.org/10.33448/rsd-v11i2.25543

Figura 6 - A) AquaTilápia. B) AquaSaúde.

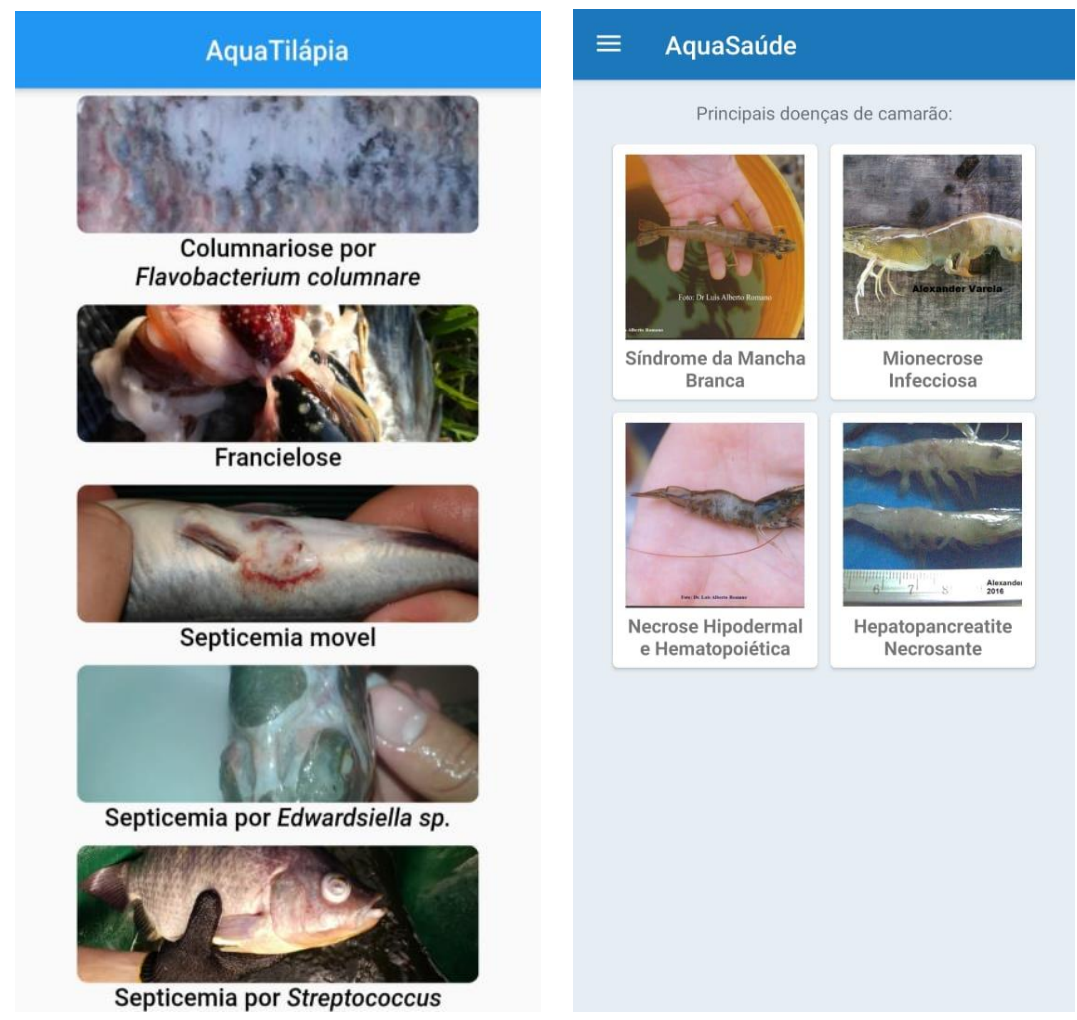

Fonte: Google Play.

O aplicativo AquaSafe é um aplicativo educacional que trata sobre a saúde e a segurança dos trabalhadores na Aquicultura (Figura 7).

Figura 7 - AquaSafe.

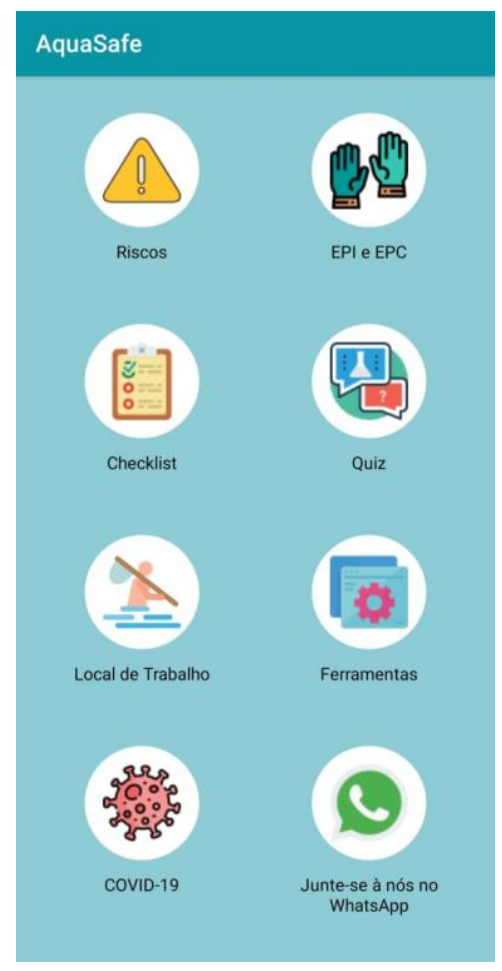

Fonte: Google Play. 
A Tabela 1 contém o resumo dos softwares e aplicativos relacionados à produção do pescado apresentados anteriormente.

Tabela 1 - Softwares e aplicativos para a produção do pescado.

\begin{tabular}{|c|c|c|c|c|}
\hline \multicolumn{4}{|c|}{ Avaliação do sistema de produção } & Link de acesso \\
\hline Aquisys v.1.3 & Tilápia & Português & Gratuito & https://www.cnpma.embrapa.br/aquisys/ \\
\hline Aquímetro & Camarões & Português & Gratuito & $\begin{array}{l}\text { https://play.google.com/store/apps/details?id=com.farmte } \\
\text { ch.aquimetro }\end{array}$ \\
\hline AquiNutri & $\begin{array}{l}\text { Tilápia, Pacu, Carpa e } \\
\text { Tambaqui }\end{array}$ & Português & Gratuito & $\begin{array}{l}\text { https://play.google.com/store/apps/details?id=appinventor } \\
\text {.ai_elton_asmartins.Quantidade_de_Racao_02_10_2017 }\end{array}$ \\
\hline Aquabit & $\begin{array}{l}\text { Camarões, peixes e } \\
\text { ornamentais }\end{array}$ & Português & Pago & https://www.aquabit.com.br/ \\
\hline Aquaweb da FCA & Camarões e peixes & Português & Pago & http://fcatec.com/aquaweb/ \\
\hline InovaPeixe & Peixes & Português & Pago & $\begin{array}{l}\text { https://play.google.com/store/apps/details?id=br.com.agro } \\
\text { inova }\end{array}$ \\
\hline BlueAqua & Camarões & Inglês & Gratuito & $\begin{array}{l}\text { https://play.google.com/store/apps/details?id=com.owamo } \\
\text {.blueaqua.android }\end{array}$ \\
\hline Growel Aqua 360 & Camarões e peixes & Inglês & Gratuito & $\begin{array}{l}\text { https://play.google.com/store/apps/details?id=com.growel } \\
\text { aquaservices.aqua360\&hl=pt_BR\&gl=US }\end{array}$ \\
\hline CIBA Shrimp Krishi & Camarões & Inglês & Gratuito & $\begin{array}{l}\text { https://play.google.com/store/apps/details?id=com.ciba.far } \\
\text { mrecord\&hl=pt_BR\&gl=US }\end{array}$ \\
\hline Aquaconnect & Camarões e peixes & Inglês & Pago & $\begin{array}{l}\text { https://play.google.com/store/apps/details?id=org.cari.far } \\
\text { m_mojo\&hl=pt_BR\&gl=US }\end{array}$ \\
\hline PondGuard & Camarões e peixes & Inglês & Pago & $\begin{array}{l}\text { https://play.google.com/store/apps/details?id=com.eruvak } \\
\text { a.pondguard }\end{array}$ \\
\hline \multicolumn{5}{|l|}{ Educacional } \\
\hline AquaTilápia & Tilápia & Português & Gratuito & $\begin{array}{l}\text { https://www.canalrural.com.br/noticias/pecuaria/aplicativ } \\
\text { o-gratuito-tilapias/ }\end{array}$ \\
\hline AquaSaúde & Camarões & Português & Gratuito & $\begin{array}{l}\text { https://play.google.com/store/apps/details?id=br.gov.rs.fe } \\
\text { pagro.aquasaude_camarao }\end{array}$ \\
\hline AquaSafe & $\begin{array}{l}\text { Saúde e à segurança do } \\
\text { trabalhador na aquicultura }\end{array}$ & Português & Gratuito & $\begin{array}{l}\text { https://play.google.com/store/apps/details?id=br.gov.rs.dd } \\
\text { pa_seapi.aquasaude.aquasafe }\end{array}$ \\
\hline
\end{tabular}

Fonte: Elaborado pelos autores.

Para maior eficiência no setor de produção, programadores já tem desenvolvido protótipos para interligar um sistema software automático a um sistema hardware, ou seja, os softwares de controle da produção estariam vinculados a maquinários automatizados como alimentadores inteligentes, sensores de tanques, câmeras e outras tecnologias, resultando assim em um sistema totalmente autônomo (Leal Junior, 2019; Dantas Filho et al., 2021).

\subsection{Informatização no setor de processamento do pescado no Brasil}

É evidente que a informatização tem alcançado o setor de processamento do pescado em larga escala. Isso porque as indústrias de processamento de pescado, têm apostado cada vez mais em inovações de maquinários sistematizados, tecnificados e "inteligentes". Automatizando assim, boa parte ou todo o processo, desde o recebimento da matéria-prima até a expedição do produto acabado. Em muitos empreendimentos os maquinários quase que substituem por completo o trabalho braçal. Dessa forma, diminui a necessidade de contratação de mão de obra (TORFRESMA, 2020). Pouco se ouve falar do uso de aplicativos nessa fase da cadeia produtiva, no entanto softwares têm sido desenvolvidos para atender as necessidades desse setor.

O software AgroPesca (Figura 8) controla todo o processo, desde o recebimento do pescado, mapa de pesca, gerencia os estoques de produtos por local de estoque, registra a armazenagem em túneis de congelamento e câmaras frias, monitora indicadores de qualidade como temperatura, $\mathrm{pH}$ da água, inspeções sanitárias, e faz a expedição do produto permitindo que seja feito recall dos lotes por cliente, e gera relatórios de rastreabilidade (AGROMAGER, 2017). 
Figura 8 - Software AgroPesca.

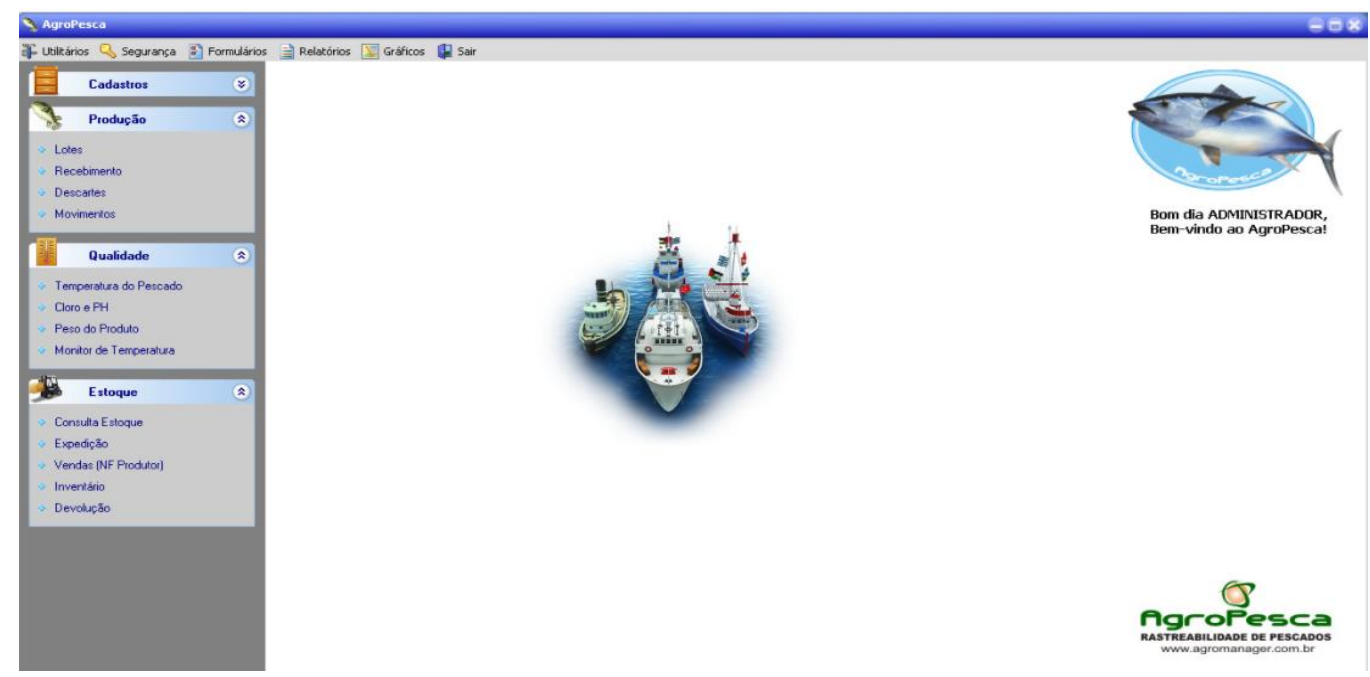

Fonte: AGROMAGER (2017).

A Tabela 2 contém o resumo dos softwares relacionados ao setor de processamento do pescado no Brasil.

Tabela 2 - Software relacionado ao setor de processamento do pescado no Brasil.

\begin{tabular}{|c|c|c|c|c|}
\hline Produto & Espécies & Idioma & Disponibilidade & Link de acesso \\
\hline AgroPesca & $\begin{array}{l}\text { Não } \\
\text { informado }\end{array}$ & & Pago & $\begin{array}{l}\text { http://www.agromanager.com.br/solucoes/pescado/agrop } \\
\text { esca }\end{array}$ \\
\hline
\end{tabular}

Fonte: Autores.

\subsection{Informatização no setor de distribuição do pescado}

Diferente do setor de processamento de pescado, o setor de distribuição ainda depende muito de mão de obra humana, visto que até muito recentemente, quase $100 \%$ das vendas eram realizadas de forma pessoal e direta, seja em grandes distribuidoras, mercados, feiras municipais ou diretamente do produtor (SEBRAE, 2020). Mas, isso não quer dizer que a informatização não chegou ao setor de distribuição, muito pelo contrário, a utilização de softwares tem sido cada vez mais aceita por grandes distribuidoras, mercados e atacadistas, visto a necessidade urgente de organização das vendas, controle de caixa e acompanhamento do lucro. Um exemplo disso é o sistema de mercado ALUMI PESCADOS (Figura 9) que foi desenvolvido especificamente para empresas de comércio e distribuição de pescado (GEPER, 2020). 
Figura 9 - Software ALUMI PESCADOS.

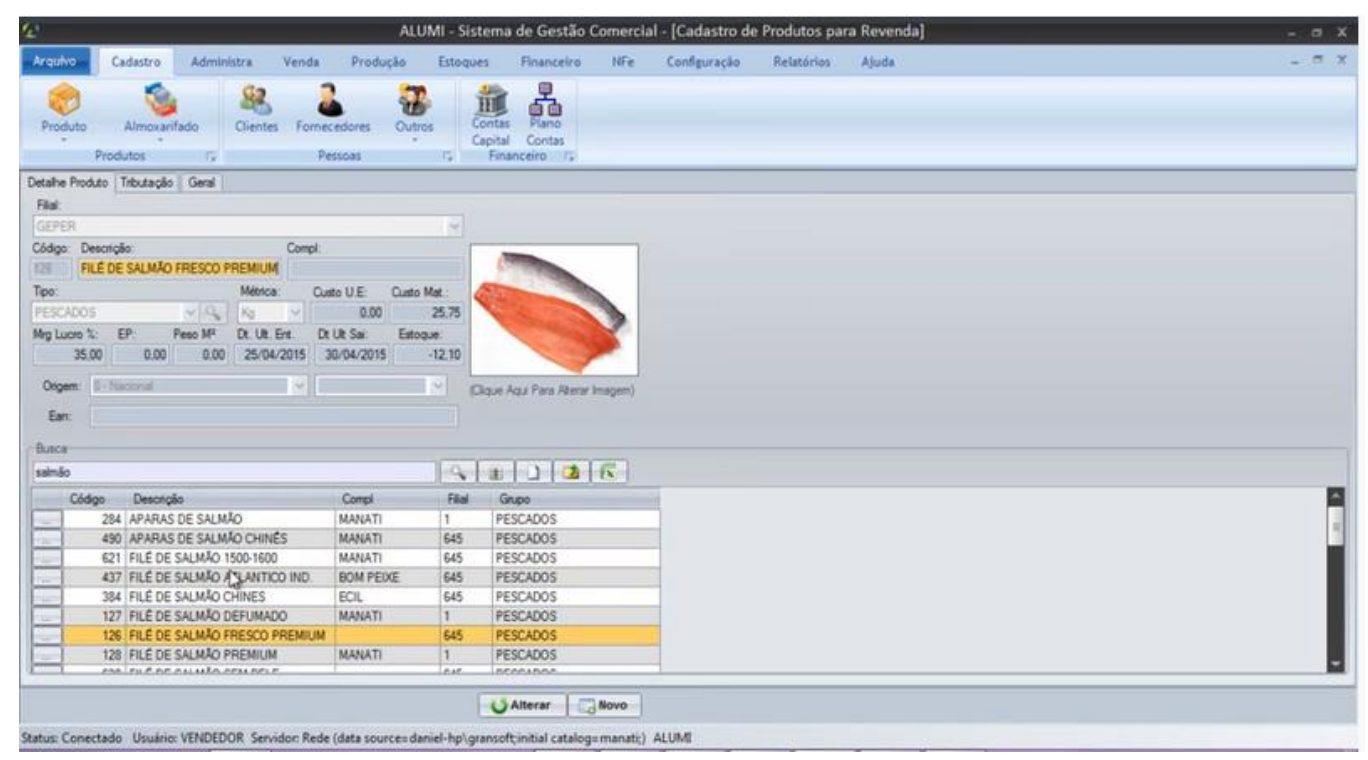

Fonte: GEPER (2020).

O sistema gerencia compra e venda e suas principais funções são gerir a venda de seus clientes, analisar o histórico de preços e quantidades, e otimizar a margem de lucro da empresa. Além dessas funcionalidades, o sistema também emite nota fiscal eletrônica de forma facilitada. Cada módulo do sistema é bem simples e intuitivo, de forma a facilitar o uso, agilizando as tarefas diárias. Suas principais características são: Sistema Multi-Empresas (Controle de Estoque por Filiais), Financeiro Completo, Emissão de NFe e NFCe de acordo com a venda, Tabela de Preços e Histórico por Compra (GEPER, 2020).

Outra inovação no setor de distribuição de pescado e que tem ganhado espaço no mercado recentemente é o uso de aplicativos para compra de pescado de maneira delivery. Até então o uso desse tipo de tecnologia era pouco comum no setor de distribuição de pescado. No entanto, no período de quarentena estabelecida devido a pandemia causada pelo Coronavírus (Sars$\mathrm{CoV}$-2) e devido à necessidade de fechamento das feiras regionais, o uso de aplicativos para serviços delivery foram a saída, inclusive para o setor de compra e venda de pescado (FOLHA, 2020; Dantas Filho et al., 2021).

Apesar de não estar mais disponível para acesso à plataforma Santa Quarentena que foi criada pela Seafood Brasil, em parceria com a Dupeixe em 2020 (Figura 10) é um exemplo de tecnologia para conectar fornecedores de pescado aos clientes. A ferramenta, criada especialmente para atender a demanda de pescado da semana santa, permitiu a inscrição ilimitada e gratuita de pontos de comercialização de pescado, que podiam oferecer condições especiais para supermercados, peixarias, food service, mercados públicos, feiras e até a opção de comprar direto do produtor. 
Figura 10 - Anúncio da Plataforma Santa Quarentena na página da Seafood Brasil no Facebook.

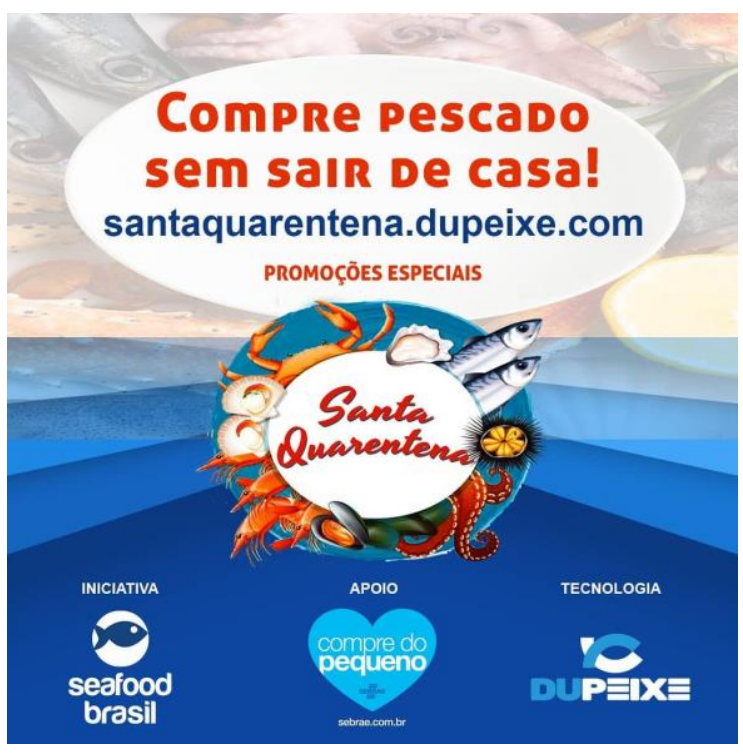

Fonte: SEAFOOD Brasil (2020).

O site para o consumidor Santa Quarentena, lançado em março de 2020 ofereceu ainda dicas variadas para os comerciantes do setor ou consumidores. O aquicultor ou pescador, por exemplo, pôde cadastrar seu Whatsapp para receber pedidos de pescado fresco direto do consumidor final. Para as indústrias foi recomendado o cadastro de todas as ofertas de pescado negociadas com os distribuidores regionais e parceiros como grandes, médios e pequenos varejos, restaurantes e peixarias. O distribuidor pôde reforçar o contato com seu fornecedor, cadastrar seu telefone para receber pedidos de pequenos varejos, peixarias, feirantes e dos restaurantes que fizeram entregas no período (Freire \& Shecaira, 2020; SEBRAE, 2020; Dantas Filho et al., 2021).

\subsection{Informatização no processo de rastreabilidade}

O pescado por ser um produto de origem animal segue a norma interna DIPOA/SDA n ${ }^{\circ} 01$, de 08 de março de 2017 do Ministério da Agricultura, Pecuária e Abastecimento (MAPA) que tem a Rastreabilidade e Recolhimento como um de seus elementos de inspeção e, portanto a indústria de pescado deve garantir que esse elemento seja atendido (Sousa et al., 2020; Barbosa et al., 2021).

A rastreabilidade nada mais é do que a ligação entre as diferentes fases da cadeia produtiva do pescado, possibilitando rastreá-lo desde a sua origem até o consumidor final. Envolve também o registro do histórico do produto, monitoramento das condições da produção e processamento, controle do processo de distribuição e comercialização, até o consumidor final. A rastreabilidade garante indiretamente não só segurança em toda a cadeia produtiva como dá ao consumidor a certeza de que está adquirindo um produto de qualidade para consumo (Mattos et al., 2014; Dantas Filho et al., 2021). Os softwares utilizados pela indústria de pescado possibilitam o atendimento dessa demanda exigida pelo MAPA, como é o caso do AgroPesca supramencionado (Signor, 2014). Com um sistema informatizado de rastreabilidade do pescado no Brasil, o país que está em processo de crescimento no que diz respeito à produção e exportação do pescado, ganhando ainda mais destaque e confiança no mercado internacional, visto que oferece um produto registrado e com qualidade certificada (Galvão, 2011; Barbosa et al., 2021).

A rastreabilidade pode e deve estar interligada ao uso de novas tecnologias, como por exemplo, os códigos bidimensionais (QR Code) ou Código de Barras em duas dimensões, cuja leitura é feita por meio de smartphone (Figura 11). Esses códigos possuem a capacidade de armazenar um grande número de informações sobre o produto oferecido, permitindo que o consumidor conheça todas as características do produto adquirido (Galvão et al, 2012; Barbosa et al., 2021). 
Figura 11 - Exemplo de emprego de código bidirecional.

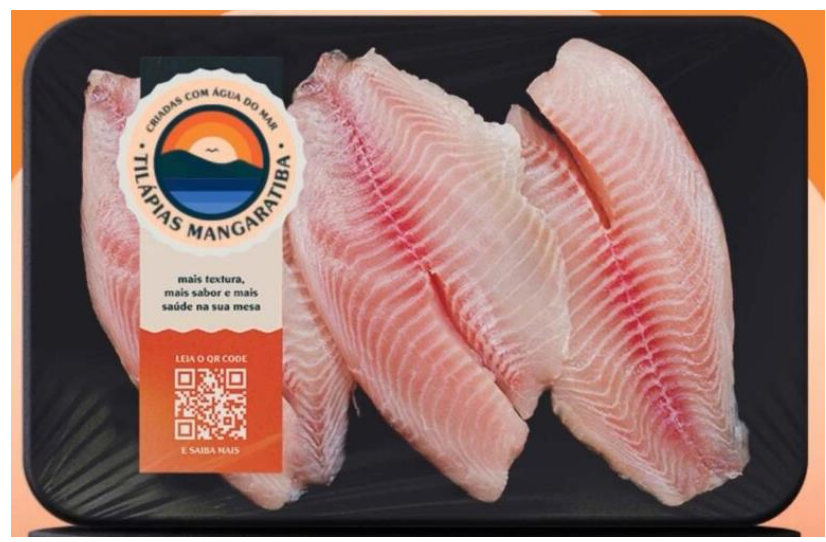

Fonte: Gastronomia Carioca (2021).

\section{Considerações Finais}

Foram encontrados sistemas informatizados, softwares, aplicativos, programas de monitoramento e outros, nas áreas de produção, no setor de processamento, distribuição e rastreabilidade do pescado. Dos sistemas e aplicativos utilizados na produção de pescado o único encontrado que aborda os peixes nativos é o AquiNutri. Os sistemas utilizados na indústria, como o software AgroPesca, são fundamentais para o controle de toda a produção e para o rastreamento dos produtos acabados. Sistemas como o ALUMI PESCADOS fazem com que o setor de distribuição atue com eficiência para que o produto elaborado pela indústria chegue rápido ao consumidor. Os códigos bidimensionais fazem com que informações relacionadas ao produto estejam mais acessíveis aos consumidores que estão cada vez mais preocupados com a ética e a sustentabilidade relacionadas a produção dos alimentos.

Apesar de existirem sistemas informatizados para a cadeia produtiva do pescado há necessidade de melhorias nos sistemas que são gratuitos e maior divulgação e módulos de teste mais acessíveis para os que são pagos. Os sistemas são elaborados para auxiliar os produtores, mas não substituem profissionais da área. O Brasil já é destaque na exportação mundial de produtos agropecuários e pode aumentar a produção nacional de produtos piscícolas por meio da implementação das tecnologias existentes.

\section{Agradecimentos}

Agradecimentos ao Programa de Pós-Graduação em Sanidade e Produção Animal Sustentável na Amazônia Ocidental, Universidade Federal do Acre (PPGESPA/UFAC), por oportunizar a realização desse manuscrito como atividade da disciplina de Produção de Peixes Nativos Comerciais. Sob condução dos Professores Dra. Jucilene Cavali e Dr. Marlos Oliveira Porto.

\section{Referências}

AGROMANAGER SISTEMAS. (2017). Agropesca: rastreabilidade do pescado. <http://www.agromanager.com.br/solucoes/pescado/agropesca

Brasil. Ministério da Agricultura, Pecuária e Abastecimento. (2017). Decreto $n^{\circ}$ 9.013, de março de 2017. Aprova o Regulamento da inspeção e sanitária de produtos de origem animal (RIISPOA). Diário Oficial da União: Brasília, DF, edição 62, seção 1, 2017, p. 3-27.

Brasil. Ministério da Agricultura, Pecuária e Abastecimento. Secretaria de Defesa Agropecuária. Departamento de Inspeção de Produtos de Origem Animal. (2020). Norma Interna $\mathrm{n}^{\circ} 1$, de 8 de março de 2017. Aprova os modelos de formulários, estabelece as frequências e as amostragens mínimas a serem utilizadas na inspeção e fiscalização, para verificação oficial dos autocontroles implantados pelos estabelecimentos de produtos de origem animal registrados (SIF) ou relacionados (ER) junto ao DIPOA/SDA, bem como o manual de procedimentos. CNA. [Panorama do agro. 2020]. <https://www.cnabrasil.org.br/cna/panoramado-agro> 
Barbosa, B. C. F., Rossi, G. A. M. \& Souza, B. M. S. (2021). Atualizações do regulamento de inspeção industrial e sanitária de produtos de origem animal (RIISPOA): o que mudou na inspeção higiênico-sanitária no Brasil? Ars Veterinaria, 37(2): 87-98. http://dx.doi.org/10.15361/2175-0106.2021v37n2p87-98

Cavali, J., Nunes, C. T., Dantas Filho, J. V., Nóbrega, B. A., Pontuschka, R. B., Souza, M. L. R. \& Porto, M. O. (2021). Chemical composition of commercial cuts of pirarucu (Arapaima gigas) processed in different weight classes in the Western Amazon. Revista Ibero-Americana de Ciências Ambientais, 12(4): 616626. https://doi.org/10.6008/CBPC2179-6858.2021.004.0048

Dantas Filho, J. V., Cavali, J., Nunes, C. T., Nóbrega, B. A., Gasparini, L. R. F., Souza, M. L. R., Porto, M. O., Rosa, B. L., Gasparotto, P. H. G. \& Pontuschka, R. B. (2021). Proximal composition, caloric value and price-nutrients correlation of comercial cuts of tambaqui (Colossoma macropomum) and pirarucu (Arapaima gigas) in diferente body weight classes (Amazon: Brazil). Research, Society and Development, 10(1), p. e23510111698. https://doi.org/10.33448/rsdv10i1.11698

Dantas Filho, J. V., Cavali, J., Gotardi, D. G. \& Schons, S. V. (2021). Immunological and biossensory techniques for detection of Salmonella spp. in food derived from fish farming- review. Arquivos de Ciências Veterinárias e Zoologia da UNIPAR, 24(2): e2406. https://doi.org/10.25110/arqvet.v24i2cont.2021.8639

EMBRAPA. Empresa Brasileira de Pesquisa Agropecuária. (2019). Aquisys v.1.3 é finalista em prêmio de inovação aquícola. <https://www.embrapa.br/buscade-noticias/-/noticia/42642840/aquisys-v13-e-finalista-em-premio-de-inovacao-aquicola>

EMBRAPA. Empresa Brasileira de Pesquisa Agropecuária. (2014). Embrapa mostra tecnologias para piscicultura na AGROBRASÍLIA. <https://www.embrapa.br/busca-de-noticias/-/noticia/1728213/embrapa-mostra-tecnologias-para-piscicultura-na-agrobrasilia>

EMBRAPA. Empresa Brasileira de Pesquisa Agropecuária. (2020). O protagonismo do Brasil na produção mundial de pescado. <https://www.embrapa.br/busca-de-noticias/-/noticia/53738345/artigo---o-protagonismo-do-brasil-na-producao-mundial-de-pescado>

EMBRAPA. Empresa Brasileira de Pesquisa Agropecuária. 2015. Soluções Tecnológicas. <https://www.embrapa.br/busca-de-solucoes-tecnologicas/-/produtoservico/2582/aquisys---aquisys-v13>

EMBRAPA. Empresa Brasileira de Pesquisa Agropecuária. 2015. AQUISYS v.1.3 - Sistema informatizado de apoio às boas práticas de manejo e gestão ambiental da aquicultura. <https://www.cnpma.embrapa.br/aquisys/>

FAO. Organização das Nações Unidas para a Alimentação e a Agricultura. 2020. The State of World Fisheries and Aquaculture 2020. Sustainability in action. Rome. 2020. 〈http://www.fao.org/3/ca9229en/ca9229en.pdf>

Folha De S. Paulo. (2020). Delivery de peixe fresco é saída para fornecedores na pandemia, <https://www1.folha.uol.com.br/mpme/2020/08/delivery-de-peixefresco-e-saida-para-fornecedores-na-pandemia.shtml>

Freire, C. E. C. A. \& Shecaira, C. L. (2020). A importância da rastreabilidade dos alimentos de origem animal frente aos surtos alimentares: Revisão. Publicações em Medicina Veterinária, 14(11): 1-8. https://doi.org/10.31533/pubvet.v14n11a682.1-8

Galvão, J. (2011). A. Rastreabilidade da cadeia produtiva do pescado: avaliação de parâmetros ambientais e sua influência na qualidade da matéria-prima destinada à indústria. 203 f. Tese (Doutorado) - Centro de Energia Nuclear na Agricultura, Universidade de São Paulo, Piracicaba, 2011.

Galvão, J. A., Maciel, E. S.\& Oetterer, M. (2012). Rastreabilidade permite busca de soluções para inconformidades. Sanidade $e$ Qualidade. 〈https://www.esalq.usp.br/visaoagricola/sites/default/files/va11-sanidade-e-qualidade03.pdf >

GEPER. Alumi: Software para distribuição de pescados. (2020). <http://www.gepersistemas.com.br/content/30/Sistema-para-Controle-e-Distribuicao-dePescados/>

Gastronomia Carioca. (2021). Conheça 5 peixes mais consumidos na gastronomia brasileira. <https://gastronomiacarioca.zonasul.com.br/5-peixes-mais-consumidos-nagastronomia-brasileira/>

Leal Junior, W., Landim, N. M. D., Nunes, R. M. \& Araujo, H. X. (2019). Projeto de um sistema de automação para piscicultura utilizando internet das coisas - IOT. Revista Científica Semana Acadêmica, 162(1): e 000162. https://semanaacademica.org.br/system/files/artigos/artigo_wilmar_revisado.pdf

Mattos, B. O., Costa, R. L. \& Bueno, G. W. (2014). Processo de rastreabilidade e certificação do cultivo de ostras (Crassostrea gigas): a primeira fazenda de ostras certificada no Brasil. Revista Ibero-Americana de Ciências Ambientais, 5(2): 123-131. https://doi.org/10.6008/SPC2179-6858.2014.002.0012

Moreira, A. G. L. \& Moreira, R. T. (2017). Softwares e aplicativos na Aquicultura: Ferramentas disponíveis e tendências futuras. Aquaculture Brasil. <https://d335luupugsy2.cloudfront.net/cms/files/85938/1593532533Softwares_e_aplicativos_na_Aquicultura_Ferramentas_disponveis_e_tendncias_futuras.p df $>$

OECD/FAO. Organização para a Cooperação e Desenvolvimento Econômico/ Organização das Naçães Unidas para a Alimentação e a Agricultura. (2016). Agricultural Outlook 2016-2025. OECD Publishing Paris. <http://www.fao.org/3/a-i5778e.pdf>

PEIXE BR. Associação Brasileira da Piscicultura. (2020). Anuário 2020: Peixe BR da Piscicultura. Pinheiros-SP: PEIXE BR; 136p. $<$ https://www.peixebr.com.br/anuario-2020/>

Pizzani, L., Silva, R. C., Bello, S. F. \& Hayashi, M. C. P. I. (2012). A arte da pesquisa bibliográfica na busca do conhecimento. Revista Digital de Biblioteconomia e Ciência da Informação, 10(1): 53-66. https://doi.org/10.20396/rdbci.v10i1.1896

Rocha, C. S., Christo B. G. \& Adalgisa, A. S. (2005). O uso da análise de conteúdo como uma ferramenta para a pesquisa qualitativa: descrição e aplicação do método. Revista Organizações Rurais \& Agroindustriais, 7(1): 70-81. https://www.redalyc.org/pdf/878/87817147006.pdf

SEAFOOD BRASIL. Página da Seafood Brasil no Facebook. (2020). <https://www.facebook.com/SeafoodBrasil/photos/a-p\%C3\%A1scoa-j\%C3\%A1-chegoumas-a-santa-quarentena-acaba-de-come\%C3\%A7aro-site-da-santa-quaren/3086048791486341> 
Research, Society and Development, v. 11, n. 2, e28911225543, 2022

(CC BY 4.0) | ISSN 2525-3409 | DOI: http://dx.doi.org/10.33448/rsd-v11i2.25543

SEBRAE. Serviço Brasileiro de Apoio às Micro e Pequenas Empresas. (2020). Sebrae recomenda delivery para venda do pescado na Semana Santa. <http://www.agenciasebrae.com.br/sites/asn/uf/NA/sebrae-recomenda-delivery-para-venda-do-pescado-na-semanasanta,aa6e2c4690161710VgnVCM1000 004c00210aRCRD>

SEBRAE. Serviço Brasileiro de Apoio às Micro e Pequenas Empresas. (2020). Como funciona o comércio de peixe no Brasil. <https://www.sebrae.com.br/sites/PortalSebrae/artigos/artigosOrganizacao/saiba-como-funciona-comercio-de-peixes-nobrasil,8bc238e243312510VgnVCM1000004c00210aRCRD>

Sousa, C. L., Lourenço, L. \& LeHalle, A. (2020). Utilização de análise de perigos e pontos críticos para garantia da segurança de alimentos: estudo de caso em uma indústria de pescado. Brazilian Journal of Production Engineering, 6(3): 30-41. https://periodicos.ufes.br/bjpe/article/view/29263

Toledo, L. A. \& Shiaishi, G. F. (2009). Estudo de caso em pesquisas exploratórias qualitativas: um ensaio para a proposta de protocolo do estudo de caso. Revista da FAE, 12(1): 103-119. https://revistafae.fae.edu/revistafae/article/view/288/195

TORFRESMA INDUSTRIAL. (2020). Uma nova era no processamento de pescados. 〈https://www.torfresma.com.br/processamentodepescados> 